\title{
Desarrollo y modernización. Un estudio comparado entre las comunidades autónomas de Andalucía y Cataluña
}

\author{
Rafael Gobernado Arribas \\ Universidad de Málaga. Departamento de Derecho del Estado y Sociología \\ gobernado@uma.es
}

Recibido: 23-01-2008

Aceptado: 01-07-2008

\section{Resumen}

Nuestro objetivo es conocer el grado de desarrollo de Andalucía. Para ello, se han seguido dos caminos conjuntamente: por un lado, un estudio comparativo con otra comunidad más desarrollada: Cataluña; por otro, la revalidación con la teoría de la modernización. En el primer caso, se han cotejado las medias aritméticas de diversas variables propias del desarrollo, tanto de Andalucía como de Cataluña, de los años 1995 y 2006, y se han calculado las posibilidades de convergencia entre las dos comunidades. En el segundo caso, se han estudiado medidas de dispersión sobre las medias, en tanto que indicadores de individuación y, por lo tanto, de modernización. De acuerdo con los datos, Andalucía mejora sus posiciones en los últimos diez años, pero Cataluña mejora mucho más, va más deprisa, pero a costa de perder algo de esa individuación.

Palabras clave: convergencia, indicadores de desarrollo, desigualdad de ingresos.

Abstract. Development and modernization. A comparative study between the autonomous communities of Andalusia and Catalonia

The aim of this research was to know the degree of development of Andalusia. In order to do so, we followed two joint paths: on the one hand, a comparative study with a more developed community; on the other, its validation according to the modernization theory. According to the first, we checked the arithmetic means of several development variables both in Andalusia and Catalonia in 1995 and in 2006. In compliance with the second, we studied dispersal measures of the arithmetic means as indicators (signs) of individuation and, therefore, of modernization. According to the information gathered, Andalusia improves its position in the last ten years, but Catalonia's improvement is much better, goes faster, but at the expense of losing some of that individuation.

Key words: convergence (agreement), indicators (signs) of development, income inequality.

\section{Sumario}

1. Objetivos y antecedentes

2. La modernización desde después

3. Los datos sobre la convergencia
4. La individuación

5. Conclusiones

Referencias bibliográficas 


\section{Objetivos y antecedentes}

El presente texto se enmarca en otro más amplio dedicado al estudio del cambio social en Andalucía ${ }^{1}$ y al que sirve de introducción. Lo que nos interesa ahora de tal cambio social es aquel aspecto del mismo que tiene que ver con el desarrollo socioeconómico. Concretando aún más, nuestro objetivo en el texto que sigue es comprobar dos dimensiones del desarrollo en Andalucía en estos últimos diez años: $a$ ) si se produce la supuesta convergencia con otra comunidad autónoma más desarrollada, y $b$ ) si tiene lugar el proceso de individuación propio de la modernización del sistema social. Ambas dimensiones permiten constatar indirectamente tanto la dirección como la velocidad del desarrollo. En último extremo, al tratar la convergencia, utilizamos medias aritméticas de diferentes indicadores de desarrollo; al tratar la individuación, usamos algunos indicadores de dispersión o desigualdad complementarios.

En último extremo, se trata de proporcionar una visión general de las diferencias entre las dos comunidades autónomas estudiadas: Andalucía y Cataluña. Seguramente, la explicación más convincente de la desigualdad en cuestión es doble: por un lado, la ubicación de ambas comunidades, una al lado de Francia y otra junto a Marruecos. Es obvio que la influencia cultural, social, política y económica en ambas comunidades tiene mucho que ver con esa localización. Pero además, y quizás también relacionado con lo anterior, otro rasgo distintivo es la gran falta de inversión educativa en Andalucía hasta épocas muy recientes. Cataluña lleva muchos años de ventaja en esa cuestión y eso se nota. Esa desigualdad educativa tiene que ver, en último extremo, con la minoría rectora local. En las páginas que siguen, hemos limitado el análisis al nivel social, se prescinde del nivel cultural que tanto interés tiene, pero que se deja para otros autores. Se trata de dar una visión global de la diferencia entre Andalucía y Cataluña, que se completará con más detalle posteriormente en sucesivos artículos.

Se han seguido dos métodos para alcanzar los objetivos indicados, de acuerdo con las dos formas clásicas de entender el desarrollo y la modernización (Sztompka, 1995: 93-04) $)^{2}$. Por un lado, se ha llevado a cabo un método comparativo: se han cote-

1. El trabajo global está subvencionado por la Fundación Centro de Estudios Andaluces (Ref. SOCH1.07/023), entidad dependiente de la Consejería de la Presidencia de la Junta de Andalucía.

2. El concepto de desarrollo es polémico. Como ya indicó Raymond Aron (1996: 587-590) en un texto clásico del tema, Trois essais sur l'áge industrial, de 1966, la teoría del desarrollo tiene tres orígenes y cada uno de ellos sugiere una interpretación diferente del término. El primer origen tiene que ver con el estudio estadístico del crecimiento económico a largo plazo. Se remonta al libro del economista australiano Colin Clark titulado Conditions of economic progress, de 1940. Este enfoque supone una visión unilineal y cuantitativa del cambio. El producto interior bruto se convierte en la variable básica del análisis. Esto supone una idea simple de progreso en la que se confunde, siguiendo a Aron, "crecimiento», "desarrollo" y "progreso». El segundo origen se basa en los estudios comparativos entre países ricos y países pobres. En general, supone análisis cualitativos además de cuantitativos. En estos estudios comparativos, se relacionan variables de diversa índole para establecer relaciones causales 
jado los indicadores de desarrollo de Andalucía con los de otra comunidad autónoma considerada más desarrollada: Cataluña. Así mismo, se ha realizado la comparación entre un antes y un después (1995 y 2005, en lo posible).

En general, la sociología del desarrollo ha dado especial importancia al método comparativo, entre otras razones, por el «marcado carácter práctico» de esa rama sociológica, tal y como lo indican López y Uldemolins (2007: 669670). Pero también este método se aprovecha del carácter cuantitativo del sistema de indicadores de desarrollo, enraizado más en la economía que en la sociología. Tal sistema de indicadores facilita y estimula la comparación. De cualquier forma, el análisis del cambio social, en sus variadas manifestaciones (desarrollo, modernización y progreso, por ejemplo), se ha basado ampliamente en el método comparativo. Los antecedentes inmediatos del presente trabajo son precisamente de este tipo (Gobernado, 1996a; Requena, 1999). (Sobre las críticas al método comparativo, véase Goldthorpe, 2007a: 39-60.)

Por otro lado, hemos utilizado un criterio teórico de desarrollo para calibrar la existencia del mismo. Como se sabe, hay tres paradigmas analíticos principales que explican el desarrollo socioeconómico desde la sociología: la teoría de la modernización (véanse Carnero Arbat, 1992; Inkeles, 1960; Eisenstadt, 1964; Deutsch, 1961; Solé, 1976 y 1987, entre otros), la de la dependencia (Cardoso y Faletto, 1979) y la del sistema mundial (Wallerstein, 1984; Rossem, 1996; Arrigi y Silver, 2001). La teoría de la modernización es la que más interés ha despertado, tanto entre los estudiosos como entre los políticos y las instituciones que éstos regentan (Roberts et al., 1995).

La teoría de la modernización supone una serie de postulados que conviene recordar (Roberts et al., 1995). Las unidades de análisis son estados, países o regiones. En nuestro caso, son dos comunidades autónomas (Andalucía y Cataluña). Se trabaja con medias aritméticas de tales países que, se da por supuesto, representan a dichos países. Se admite la idea de la convergencia ${ }^{3}$. Todos los países van en la misma dirección. Así, la experiencia de los desarrollados sirve de orientación para los menos desarrollados. Las diferencias entre países tienen que ver sobre todo con las distintas velocidades del desarrollo. La tradición es un elemento a

de la pobreza y de la riqueza, más allá de la pura economía. El tercer origen se encuentra ya bastante lejano a nosotros: es la comparación entre el modelo de desarrollo capitalista y el comunista. Se puede reconvertir la polémica de entonces por otra de carácter teórico y más actual: si es más probable que se produzca desarrollo dejando actuar a las fuerzas sociales de forma espontánea o, por el contrario, de forma planificada.

En el texto que sigue, se tienen en cuenta esas tres posibilidades de análisis para calibrar el desarrollo socioeconómico de Andalucía, como se verá.

3. El análisis de la convergencia ha sido desarrollado sobre todo por los economistas a partir del indicador de PIB. Son muchos los trabajos actuales sobre el tema y muy variadas las técnicas de cuantificación de la misma. Los resultados generales indican que no hay tal convergencia entre los países de la Unión Europea (Boldrin y Canova, 2001) ni entre las comunidades autónomas españolas (Mancha, 2001, y Raymond, 2002). El más reciente (Marchante, Ortega y Sánchez Maldonado, 2006) distingue entre el estancamiento en la evolución del reparto de riqueza y la acusada convergencia en su índice particular de desarrollo humano ampliado. 
tener en cuenta, ya que no parece perder importancia incluso en los países desarrollados. Sin embargo, se considera tal tradición más un inconveniente que una ventaja. Si un país no se desarrolla o lo hace más lentamente, es culpa suya. El cambio hacia el desarrollo es un problema interno. Se necesita una cultura o una forma de pensar especial: racionalidad, universalismo, orientación hacia la eficacia, entre otras cosas. El libre mercado y la democracia acompañan a la modernización (Inglehart y Welzel, 2006). Todo ello se encuentra relacionado con la importancia dada a la individuación en las sociedades modernas ${ }^{4}$.

Otra idea genérica propia de la modernización, de acuerdo con la versión clásica, es la individuación: cuanto más moderna es una sociedad, más independientes son los individuos entre sí (Simmel, 1986). No se trata de un sentimiento, puesto que, si fuera así, hablaríamos de individualismo y pertenecería, por lo tanto, al nivel cultural de análisis. Por el contrario, la individuación pertenece al nivel social. La individuación es el resultado inevitable del aumento de complejidad de la división social del trabajo, y ésta pertenece al nivel social de análisis. Esto significa que cada vez hay más categorías sociales en las que ubicarse, que cada persona puede cambiar más fácilmente de una categoría a otra y que, además, esa persona puede pertenecer a muchas más categorías a la vez. Es decir, se trata de un proceso que se produce y se reproduce en el nivel de análisis social, de forma relativamente independiente del nivel de análisis cultural. Por todo ello, el desarrollo o la modernización implica que el comportamiento de los individuos es cada vez menos predecible atendiendo a las categorías sociales de pertenencia. Así, la dirección de voto, la asiduidad en las prácticas religiosas, los ingresos, los conocimientos y las habilidades, la práctica del deporte y cualquier otro tipo de comportamiento es cada vez más independiente de ser hombre o mujer, vivir en el campo o en la ciudad, tener un nivel educativo formal alto o bajo, y así sucesivamente. En resumen, la aleatoriedad en el comportamiento se convierte en un indicador de modernización (Gobernado, 1996a: 8-10) ${ }^{5}$.

4. Verdaderamente, la definición de modernidad ha sido muy variada y forma parte de la misma tradición sociológica. El surgimiento de la sociología va unido al interés por distinguir la sociedad tradicional de la sociedad moderna. Marx, Saint-Simon, Comte, Spencer, Durkheim, Weber, Tonnies y tantos otros ayudaron a definir el concepto de modernización (sobre este tema, véase Entrena Durán, 2001).

En el caso concreto de España, como señalan López y Uldemolins (2007: 667), el desarrollo socioeconómico de la sociedad se confunde con la institucionalización de la sociología. Esta confusión retrasó la aparición de la rama específica de sociología del desarrollo, ya que, cuando se estudiaba la sociedad española de los años sesenta desde la sociología, se hacía a la par sociología del desarrollo, sin tener conciencia de ello.

Industrialización, modernización, occidentalización e individualidad son procesos y cualidades que suelen ir unidos. La historia de Occidente es la historia de la modernización y del auge de la individualidad. En cierta medida, esta idea general se encuentra detrás de la teoría de la convergencia: todos vamos en la misma dirección, que es la del mundo industrializado occidental (véanse, entre otros, Black, 1979, y Kumar, 2005).

5. La idea de la individuación (propia del nivel social) y la del individualismo (propio del nivel cultural), como elementos de la modernización, se producen a la par. Ya a principios de la 
La otra cara de la moneda es que las categorías sociales propias de la división social del trabajo dejan de tener interés explicativo de esos mismos comportamientos. El sexo, la edad, el nivel educativo, la clase ocupacional, el tipo de hábitat, etc. cada vez tienen menos que ver con los comportamientos de las personas. De ahí se deduce que un indicador de desarrollo es precisamente esa falta de explicación de los comportamientos de los modelos tradicionales de la sociología. Esta relación (o la falta de la misma) sirve para apreciar la difusión de la modernización.

Según lo anterior, la igualdad de beneficios (las medias de renta y prestigio) entre las diferentes posiciones sociales (entre las múltiples categorías propias de la división social del trabajo) es un claro indicador de modernización. Los beneficios estarían desigualmente repartidos dentro de cada categoría social, dependiendo de la habilidad de cada cual para su realización. Los tratados clásicos sobre desigualdad social distinguían entre el prestigio que acompaña a las ocupaciones (por ser médico, abogado, electricista, camarero, etc.) y la estima que acompaña a los individuos según realizan mejor o peor su tarea, cualquiera que sea ésta. Una sociedad moderna es aquella en la que las desigualdades son sobre todo de estima, pero no de prestigio ${ }^{6}$.

década de 1970, Inkeles y Smith (1974) definían la modernización como un desarrollo continuo de la autonomía y la realización individual. Más recientemente, Cummins (2000) relaciona positivamente indicadores objetivos de desarrollo (nivel social de análisis) con indicadores subjetivos, entre los que destaca la individualización. Welzel e Inglehart (2005) vuelven de nuevo a la importancia del individualismo, de la búsqueda de la libertad, la democracia y el desarrollo económico.

Fox (1980: 113-134) explica la relación entre individuación e individualismo en su clásico libro sobre la familia y el parentesco. Cuando la nueva pareja pertenece tanto a la línea de parentesco de ella como a la de él (doble filiación), ambos se sienten liberados de las dependencias matrilineales o patrilineales (filización unilineal), que son mucho más potentes.

6. Entendemos, por lo tanto, que hay dos tipos de desigualdad: la que proviene de capital acumulado individualmente (conocimientos, habilidades, fuerza, salud) y la que proviene de capital acumulado colectivamente (por ser varón, por pertenecer a una familia de clase acomodada, por nacer en una ciudad en vez de en una aldea, por tener propiedades, etc.). La primera exige demostración constante de tal acumulación mediante la competencia (pensemos, por ejemplo, en los deportes, la música, conocer idiomas, habilidades manuales, conocimientos profesionales, etc.). La segunda, la que proviene de capital colectivo, no necesita su demostración ni su defensa mediante competición, opera a la manera de los blasones de nobleza, como dijo Pierre Bourdieu de los títulos educativos. Cuando, en este trabajo, se habla de individuación, nos referimos a una sociedad con menor desigualdad proveniente de la acumulación de capital colectivo y una mayor desigualdad de capital individual.

En toda sociedad hay capital acumulado de ambos tipos, pero se supone que, en las sociedades modernas, hay más capital individual y, en las tradicionales, más capital colectivo. Esto no significa que en una sociedad totalmente moderna teóricamente deje de haber desigualdad de ingresos o de prestigio, sino que tal desigualdad proviene sobre todo del capital acumulado individualmente (habilidades, conocimientos, esfuerzo, etc.). De cualquier forma, en el caso extremo teórico de una sociedad tradicional, la desigualdad proveniente del capital individual siempre será inferior a la desigualdad del capital colectivo. 
La desigualdad social, al fin y al cabo, es desigualdad de ingresos o de prestigio entre la población. Se entiende que los ingresos y el prestigio son algo así como los beneficios emanados del capital (real y metafórico) acumulado (tanto individual como colectivo). La existencia del capital colectivo se aprecia en que la distribución de los ingresos o del prestigio tiene mucho que ver con categorías sociales (sexo, edad, ocupación, sector de producción, etc.). Entre dos sociedades, aquella cuyos ingresos o prestigio tengan menos que ver con las categorías sociales indicadas (capital colectivo) estará más cerca de la modernidad.

Esto explica de paso su proceso de difusión: la modernización es un proceso que se inicia en puntos sociales concretos y se expande al resto de la sociedad. Así, comienza en las ciudades y se expande al campo, comienza en los varones y se expande a las mujeres, lo aceptan mejor los jóvenes y alcanza luego a los mayores, encaja mejor entre los que tienen un nivel educativo formal alto y se expande después al resto de la población con un nivel de educación inferior, etc. Se puede afirmar, por lo tanto, que cuando han desaparecido las diferencias de comportamiento entre categorías sociales, el desarrollo ha alcanzado a más cantidad de población. La mayor independencia de comportamiento respecto a ese tipo de variables (las categorías propias de la división social del trabajo) se convierte, por lo tanto, también en un indicador de difusión del desarrollo (Gobernado, 1999a: 32-49).

Como se dijo más arriba, en última instancia, los datos sobre individuación ofrecen información de la dispersión sobre la media aritmética de algunas de las variables usadas en el análisis de convergencia.

\section{La modernización desde después}

Hace treinta años, la teoría de la modernización respondía aceptablemente bien a la realidad. Sin embargo, las cosas han cambiado algo desde entonces. Las etiquetas se han multiplicado. Se habla ahora de postindustrialización, postmodernismo, postfordismo, sociedad de la información, de globalización, de capitalismo desorganizado, etc. En general, todas estas etiquetas, cuyos significados tienen mucho en común, se refieren a una situación bastante más desordenada e imprevisible que la anterior, la de la simple modernización.

Es obvio que el desarrollo no es un proceso unilineal, ni seguramente tiende a la convergencia en la mayor parte de las variables sociales. Además, hemos asistido, en los últimos treinta años, a un conjunto de cambios tecnológicos, políticos y económicos extraordinarios que han dado un gran vuelco a la trayectoria modernizadora. Todo ello ha hecho que tanto la convergencia como la individuación, de la que se habla más arriba, hayan sido puestas en entredicho como indicadoras de modernización.

El punto de partida de nuestro análisis es la distinción entre cultura y sociedad. La mayor parte de los cambios sugeridos con las etiquetas de postmodernismo, sociedad de la información, del conocimiento, etc. tiene más que 
ver con el nivel de análisis cultural que con el de la sociedad ${ }^{7}$. La lógica que se aprecia en el orden cultural difiere de la que se observa en el social. Alexander (2000) distingue sucesivas etapas y enfoques del tratamiento del proceso cultural moderno. Más que cambios culturales, se trata de cambios en la forma de entender ese mismo cambio: moderno, postmoderno, antimoderno y neomoderno. En el fondo, esos términos denotan simplemente interés por la originalidad, por la búsqueda de la frase ingeniosa, por la distinción del autor. En otros casos sí parece haber cambios culturales propios de la modernización que se mantienen (por ejemplo, Inglehart y Welzel, 2006). De cualquier forma, la cultura se mueve de forma bastante independiente de la sociedad y con una lógica muy específica que la vuelve difícil de aprehender. (Para una interpretación, un tanto particular, de la lógica interna de los cambios culturales, véase Gobernado, 2002 y 2004.)

Lo que interesa en este artículo ahora es el cambio en el nivel social de análisis, el de la división social del trabajo. Verdaderamente, la etiqueta que adelanta cambios en tal nivel social es la de postindustrialización. Recordemos que Daniel Bell (1976) desarrolló tal etiqueta a principios de los años setenta. La sociedad de la información, continuadora de la postindustrial, es una sociedad de servicios, con un rápido crecimiento de ocupaciones de técnicos y profesionales. Dentro del sector servicios, ha aumentado, a su vez, la población activa dedicada a la información y al conocimiento.

Las diversas razones que se esgrimen en contra del proceso de convergencia y de la individuación en las sociedades modernas actuales provienen de diferentes fuentes. La idea de globalización económica es la que más argumentos proporciona en contra. (Véase un repaso complejo sobre la idea de globalización en Held y McGrew, 2003.) Así, para algunos estudiosos de la globalización, una sociedad ya desarrollada basada en el conocimiento y la comunicación generará una estructura social más desigualitaria que la anterior. Tendrá la forma de un reloj de arena: un grupo amplio de población ocupada en puestos que exigen conocimiento y responsabilidad, otro grupo mucho más amplio en la base y muy poca población en los niveles intermedios (véase Kumar, 2005: 52, en donde enumera algunos trabajos con resultados de este tipo). Otros observadores de la globalización, sin embargo, intuyen que el futuro es una sociedad sin clases, desclasada. No se trata, en

7. Kumar (2005) sugiere la existencia de tres trayectorias en el análisis del cambio social actual: la que se produce en la cultura hacia la postmodernidad; la que se produce en el nivel social hacia la sociedad de la información y que pasa previamente por la sociedad postindustrial, y, en tercer lugar, la que parte del fordismo y llega al postfordismo en la era reciente. La trayectoria intelectual de la sociedad de la información, según Kumar, es desarrollada sobre todo por el ala conservadora de la sociedad; mientras que la trayectoria del portfordismo es desarrollada por el ala izquierdista.

La trayectoria postfordista basa sus explicaciones en la política laboral seguida. Caben dos tipos de política: la orientada al capital y la orientada por estrategias negociadoras (Koch, 2006). Se supone que la política es la misma en las dos comunidades autónomas estudiadas ahora, de ahí su falta de interés para nosotros. 
este caso, de incremento de la individuación, sino que tiene que ver con la inseguridad en el empleo y la acelerada movilidad ocupacional, propias de la sociedad globalizada. Estos teóricos afirman que la forma tradicional de trabajo ha desaparecido, ya no hay carreras laborales que duren toda la vida, esto sería un "capitalismo sin trabajo». Así mismo, los teóricos de la globalización opinan que las categorías ocupacionales inferiores de los países desarrollados salen perdiendo: o aumenta el paro (como en Europa) o disminuye el salario (como en Estados Unidos de América). (Véase especialmente Beck, 2000.)

Sin embargo, los datos no se ajustan del todo a las previsiones anteriores. Parece ser que disminuyen las diferencias entre estados, pero aumentan las diferencias internas en los países ya desarrollados (Goesling, 2001). Sin embargo, persiste la forma tradicional de empleo (Goldthorpe, 2007b). Los datos no apoyan esa prevista inseguridad ni el exceso de movilidad ocupacional. En cuanto a la desigualdad económica, continua Goldthorpe, no hay tal pérdida de las categorías ocupacionales bajas. La desigualdad, que sí aumenta en los países ya desarrollados, no se debe a que disminuyan los ingresos de las categorías inferiores, sino a que aumentan exageradamente los ingresos de las categorías ocupacionales superiores. Según Goldthorpe (2007b), las explicaciones de los cambios en la desigualdad social, de acuerdo con los datos empíricos, no tiene mucho que ver con la amplitud del mercado (globalización) en estas últimas décadas, sino sobre todo con el desarrollo de nuevas tecnologías, los cambios en la organización y las variaciones demográficas.

A las anteriores razones en contra del proceso de individuación, debemos añadir otra, de carácter metodológico. Se trata de tener en cuenta la propia lógica del desarrollo socioeconómico. Este desarrollo supone un crecimiento en forma de S. En el proceso, se pueden apreciar tres etapas: la primera es el primer tramo de la $S$, en donde el desarrollo es mínimo y, por lo tanto, la igualdad es grande. El segundo tramo es el de un crecimiento evidente y en el que la desigualdad es muy acusada, especialmente justo a la mitad del recorrido ascendente. Es una etapa en la que la mitad participa del desarrollo y la otra mitad, no. Es un momento crítico de posible conflicto social. La tercera etapa se consigue cuando la mayoría de la población disfruta de la nueva situación de desarrollo. En esta etapa se supone que se ha consumado el proceso de difusión del desarrollo.

En esa tercera etapa de las consideradas es cuando se produce el nivel más acusado de individuación, mientras que en la primera etapa y en la mitad de la segunda la individuación es menor (véanse, para el caso de la menor importancia del nivel educativo, en los ingresos y en el prestigio ocupacional, a medida que sube el nivel de desarrollo, Gobernado 1996b y 1996c). Ahora bien, el desarrollo se articula en una sucesión de procesos en $S$, como el descrito anteriormente. De ahí que es posible que dos sociedades se encuentren no sólo en diferentes niveles de desarrollo, sino, además, en distintas etapas de crecimiento del mismo. La comparación, por lo tanto, se vuelve problemática. 


\section{Los datos sobre la convergencia}

Los trabajos actuales sobre desarrollo y cambio social desde la teoría de la modernización siguen tres trayectorias importantes (Welzel, Inglehart y Klingemann, 2003): los estudios de desarrollo socioeconómico, los análisis de cambio de valores y el análisis de las modificaciones institucionales propias de la modernización, caracterizadas por una mayor democracia. El texto que sigue encaja solo con la primera trayectoria: los estudios de desarrollo socioeconómico.

Según Welzel et al., el concepto de desarrollo se ha operativizado en los siguientes procesos ${ }^{8}$ : crecimiento económico, innovación tecnológica, mejora de la salud y mayor esperanza de vida, incremento de las rentas, mayor nivel educativo, mayor acceso a la información y mayor complejidad social. Ahora sólo tendremos en cuenta algunos de estos indicadores.

El punto de partida de nuestro análisis es el crecimiento económico que tuvo lugar en España hasta el año 2007. El dato se obtiene a partir de la variación interanual del producto interior bruto. Seguramente éste es el indicador más completo de desarrollo socioeconómico y, por lo tanto, de modernización (Kuznets, 1973; Todaro, 1982). Se trata de un indicador muy criticado, tanto desde la sociología como desde la propia economía. La sociología ha dirigido su crítica a que el PIB, la renta per cápita o cualquier otro indicador de riqueza es un dato que no tiene en cuenta otros rasgos sociales complementarios, ni aspectos subjetivos (Eckersley, 2000; Cummins, 2000), ni la dispersión, ni su reparto (para una visión más amplia de estos otros indicadores, vale la pena echar un vistazo al trabajo sobre la pobreza — antónimo de riqueza- de Maestro Yarza y Martínez Peinado, 2003). En otras palabras, no tiene tampoco en cuenta la desigualdad interna de cada país. Además, la riqueza pertenece también a las generaciones futuras y eso hay que tenerlo en cuenta a la hora de calcular el desarrollo (Aron, 1996; Anand y Sen, 2000; Welzel, Inglehart y Klingemann, 2003). Por su parte, algunos economistas criticaron la propia cuantificación de tal PIB (Myrdal, 1972: 218 y s.). Pese a todo, el PIB se sigue utilizando en cualquier análisis de desarrollo.

Entre los años 1995-2004 hubo un notable crecimiento económico en toda España. Este crecimiento se refleja en los datos de la Contabilidad nacional y regional del INE. En el cuadro 1, se muestran los datos globales de tal crecimiento en las comunidades autónomas comparadas. Andalucía ha crecido un

8. La operativización del desarrollo ha sido siempre problemática y los intentos de clasificar indicadores de desarrollo han sido muy numerosos. K. Deutsch (1961) señalaba los siguientes: menor número de personas por hogar, aumento de las rentas medias, aumento de la urbanización, aumento del nivel educativo, aumento del grado de alfabetización y, el último, disminución de la población ocupada en el sector primario. Merece la pena citar el interesante trabajo de A. de Miguel, J. Diez Nicolás y A. Medina Medina (1967) sobre sistemas de indicadores, en pleno desarrollismo español de la década de 1960. Por aquella época, se recrudeció también en nuestro país la polémica sobre la utilidad de tales sistemas de indicadores (S. del Campo, 1972). 
Cuadro 1. PIB (a precios constantes de 1995) según comunidad autónoma y año

\begin{tabular}{lcccl}
\hline & 1995 & 2004 & Diferencia & $\begin{array}{l}\text { Tasa de } \\
\text { crecimiento }\end{array}$ \\
\hline Andalucía & 58.703 .745 & 81.795 .188 & 23.091 .443 & 39,3 \\
Cataluña & 82.752 .572 & 106.527 .599 & 23.775 .027 & 28,7 \\
Diferencia & 24.048 .827 & 24.732 .411 & & \\
Cataluña (Andalucía =100) & 141 & 130 & \\
Convergencia & & \multicolumn{2}{c}{39} & \\
\hline
\end{tabular}

Fuente: INE. Contabilidad regional de España. Elaboración propia.

39,3 por ciento y Cataluña algo menos, un 28,7 por ciento, entre 1995 y 2004. No obstante, el PIB de Andalucía en el año 2004 no alcanza todavía al de Cataluña de diez años antes. De cualquier forma, existe la posibilidad de convergencia? entre ambas comunidades. Si todo siguiera exactamente igual, y de acuerdo con estos datos, se conseguiría la citada convergencia dentro de treinta y nueve años. En verdad, este indicador no deja de ser un dato falso si se le considera literalmente. Como todo indicador, debe ser entendido en términos relativos. Sólo sirve para compararse con otros datos semejantemente elaborados.

Tal convergencia apenas se aprecia en el gráfico 1, en el que las líneas parecen paralelas. No obstante, se desprende claramente de sus líneas la acusada tendencia de crecimiento de ambas comunidades.

Un indicador de difusión del desarrollo y, por lo tanto, también de desarrollo es la población desacoplada (Gobernado, 1994). Este indicador se forma a partir del PIB y de la población de cada comunidad. Se entiende por población

9. La convergencia $=\operatorname{logn}(\mathrm{A} 95 / \mathrm{C} 95) / \operatorname{logn}((1+\mathrm{tcC}) /(1+\mathrm{tcA}))$.

Siendo, en este caso, A95 el valor andaluz de 1995; C95 el valor catalán correspondiente en el mismo año; tcC es la tasa de crecimiento de ese valor en Cataluña en el espacio de tiempo considerado, y tcA es la tasa de crecimiento del mismo tiempo en Andalucía. El resultado se multiplica por el número de años del período considerado.

$\mathrm{El}$ indicador de convergencia oscila entre $-\infty \mathrm{y}+\infty$. No obstante, se puede considerar la proximidad al valor 100 ya muy extrema, próxima a una situación de líneas paralelas. El valor 0 se obtiene cuando se produce una coincidencia total con los datos últimos considerados. Cuando el valor es positivo, existe verdaderamente convergencia. Es decir, las líneas no son paralelas y tienden a juntarse en el futuro. Por el contrario, cuando es negativo, tampoco son paralelas, pero tienden a divergir en el futuro. El valor del número debe interpretarse de dos maneras diferentes según sea el dato positivo o negativo. Si es positivo, cuanto más pequeño sea, más próximo a 0 , antes se producirá la convergencia. En este caso, tiene sentido hablar de los años teóricos que faltan para que se produzca la convergencia. Si es negativo, la interpretación es la contraria: cuanto más próximo a cero, mayor divergencia. No tiene sentido, entonces, hablar de años pretéritos en los que tuvo lugar una posible coincidencia de datos entre Andalucía y Cataluña. En los datos negativos, se aprecia la falsedad literal del artificio estadístico. 


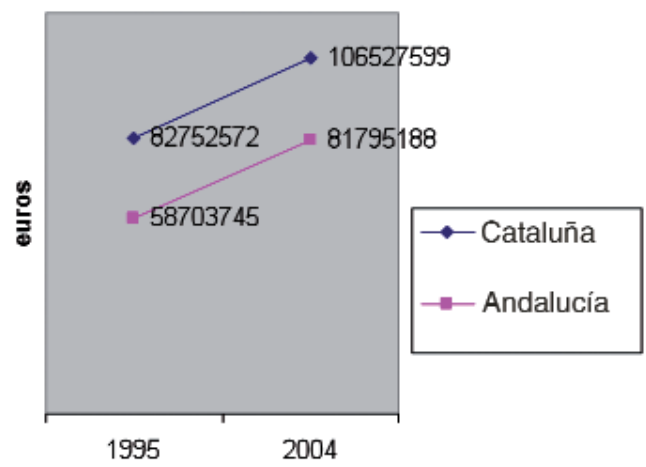

Gráfico 1. PIB (a precios constantes de 1995) según años y comunidad autónoma. Fuente: datos cuadro 1 .

Cuadro 2. Porcentajes de población y PIB sobre el total de España según comunidad autónoma y año. Población desacoplada

\begin{tabular}{|c|c|c|c|c|c|c|}
\hline & \multicolumn{3}{|l|}{1996} & \multicolumn{3}{|l|}{2004} \\
\hline & Población & PIB & Desacoplados & Población & PIB & Desacoplados \\
\hline Andalucía & $18,20 \%$ & $13,40 \%$ & 4,8 & $17,80 \%$ & $13,80 \%$ & 4 \\
\hline Cataluña & $15,40 \%$ & $19,00 \%$ & $-3,6$ & $15,80 \%$ & $18,40 \%$ & $-2,6$ \\
\hline Diferencia & 2,8 & $-5,6$ & 8,4 & 2 & $-4,6$ & 6,6 \\
\hline Cataluña $($ Andalucía $=100)$ & 85 & 142 & & 89 & 133 & \\
\hline
\end{tabular}

Fuente: INE, elaboración propia.

desacoplada la diferencia entre el porcentaje de población de cada comunidad en España y el porcentaje de participación de la riqueza de cada comunidad en España. Más concretamente, si restamos el porcentaje de población que tiene Andalucía en España del porcentaje de su participación del PIB nacional, obtenemos la población desacoplada (4 en el año 2004, según el cuadro 2). Es un indicador de desarrollo que no puede tomarse en términos literales. El dato anterior se puede interpretar de dos maneras: o sobra un 4 por ciento de población en Andalucía o falta un 4 por ciento de la participación andaluza en el PIB español. O lo que es igual: en Cataluña falta un 2,6 por ciento de población o sobra un 2,6 por ciento de su participación en el PIB nacional. Por supuesto, los términos de sobrar o faltar no se pueden tomar literalmente. Se trata de un dato que sirve para indicar una situación particular.

Una sociedad desarrollada es aquella en la que la población desacoplada tiende a desaparecer. En una sociedad moderna, en la que existe posibilidad de movilidad social y territorial, se producirá un trasvase (de población o de 
PIB) de una región a otra, de forma que tenderá a equilibrarse. En España parece que esto está ocurriendo: se pasa de 8,4 en el año 1996 a 6,6 en el 2004 (véase el cuadro 2). La proporción de desacoplados andaluces y catalanes disminuye. A Andalucía le sobra población o le falta participación en el PIB global de España. No obstante, el dato andaluz de población desacoplada en el año 2004 es menor que el de 1995. A su vez, lo contrario ocurre en Cataluña: su participación en la riqueza nacional disminuye algo o quizás es que aumenta su población. De cualquier forma, su población desacoplada también disminuye. La idea que subyace a este indicador es que la comunicación entre las comunidades opera a la manera de los vasos comunicantes cuando la sociedad es moderna y permite la movilidad social y espacial.

Más relacionado con el indicador anterior y con más interés para nuestro trabajo es el PIB por habitante que se presenta en el cuadro 3, por comunidades y años (con datos a precios constantes de 1995). (Recordemos que Andalucía tiene más población que Cataluña, alrededor de un millón de habitantes.) Pues bien, de acuerdo con ese cuadro, Cataluña sigue teniendo un PIB por habitante muy superior al de Andalucía. Esto era de suponer, ya que no sólo el monto total catalán es mayor, sino que, además, se debe distribuir entre menos gente. Incluso el dato andaluz del año 2004 sigue siendo inferior al de Cataluña del año 1995, pero en este caso, o sea con este indicador, la tasa de crecimiento es menor en las dos comunidades. La tasa de crecimiento andaluz baja ahora al 32,6 por ciento desde 1995 hasta 2004, mientras que la catalana ha descendido aún más, al 17,6 por ciento. Sin embargo, y esto es lo interesante, la diferencia de crecimiento entre las comunidades es ahora menos acusada que con el indicador global anterior. El crecimiento demográfico (otro indicador de desarrollo que veremos luego) ha atemperado el éxito catalán.

Es decir que, según los datos del cuadro 3, Andalucía se acerca más deprisa al nivel de riqueza de Cataluña. Para matizar este dato, volvemos al indicador de convergencia. Según tal indicador, existe convergencia entre las trayectorias de Cataluña y Andalucía. Más concretamente, de seguir así las cosas (algo poco probable, claro está), Andalucía tardaría 37,9 años en alcanzar el PIB de Cataluña, algo menos que anteriormente.

Cuadro 3. PIB (a precios constantes de 1995) por habitante y año (€), según comunidad autónoma

\begin{tabular}{lccll}
\hline & 1995 & 2004 & Diferencia & $\begin{array}{l}\text { Tasa de } \\
\text { crecimiento }\end{array}$ \\
\hline Andalucía & 8.026 & 10.640 & 2.614 & $32,6 \%$ \\
Cataluña & 13.290 & 15.635 & 2.345 & $17,6 \%$ \\
Diferencia & 5.264 & 4.995 & & \\
Cataluña (Andalucía = 100) & 166 & 147 & & \\
Convergencia & & & 37,9 & \\
\hline
\end{tabular}

Fuente: INE. Contabilidad regional de España. Elaboración propia. 
Cuadro 4. Productividad (PIB / población ocupada) según comunidad autónoma y año

\begin{tabular}{|c|c|c|c|c|}
\hline & 1995 & 2004 & Diferencia & $\begin{array}{l}\text { Tasa de } \\
\text { crecimiento }\end{array}$ \\
\hline Andalucía & 32.660 & 29.600 & -3.060 & $-9,4$ \\
\hline Cataluña & 37.860 & 34.290 & -3.570 & $-9,4$ \\
\hline Diferencia & 5.200 & 4.690 & & \\
\hline Cataluña $($ Andalucía $=100)$ & 116 & 116 & & \\
\hline Convergencia & \multicolumn{4}{|c|}{2001} \\
\hline
\end{tabular}

Fuente: INE. Contabilidad regional de España. Elaboración propia.

Un indicador algo más depurado de desarrollo es el nivel de productividad del sistema económico. La fórmula más fácil de definir la productividad es obtener el promedio del PIB según la población ocupada. De acuerdo con los datos del cuadro 4, la productividad de Cataluña es más alta que la de Andalucía, pero los datos tienden a parecerse mucho más que en el cuadro anterior. Las diferencias entre ambas comunidades ahora no son tan acusadas como con los datos anteriores. Merece la pena señalar que en ambas comunidades ha descendido la productividad en un 9 por ciento entre los años citados. Pero, volviendo a nuestro tema, no ha habido cambio de Andalucía respecto a Cataluña en este aspecto. Las distancias de productividad, además de escasas, siguen siendo las mismas. Se aprecia sobre todo en el indicador de convergencia: 2001. Esto significa que las líneas son casi paralelas. Seguramente, este descenso en la productividad tiene que ver con los cambios ocupacionales propios de las sociedades más evolucionadas, con una estructura en forma de reloj de arena: bastantes ocupados en los niveles altos, muchos más en los bajos y muy pocos en los del medio.

Los bajos salarios se encuentran muy relacionados también con la baja productividad. En el cuadro 5, se informa sobre la media de los mismos de acuerdo con la Encuesta anual de estructura salarial del INE. Según esos datos, los salarios han subido poco, tanto en Cataluña (el 9,1\%) como en Andalucía (el $7,5 \%$ ), sobre todo si los comparamos con el crecimiento del PIB (cuadro 1). Téngase en cuenta, además, que los datos del salario medio que se presentan aquí no están corregidos por el incremento de precios al consumo, como lo están los datos del PIB. Eso significa que el incremento real del salario medio anual es muy inferior al indicado, si no es negativo, pero esta corrección no es necesaria para hacer nuestras observaciones.

Los salarios son superiores en Cataluña, además, el crecimiento nominal de los mismos ha sido superior también en Cataluña. El dato de la convergencia es, por lo tanto, negativo, aunque las líneas son casi paralelas $(-92,4)$. La distancia entre las dos comunidades es evidente y, además, se acentúa.

La tasa de actividad también es un indicador de desarrollo. Cuanto más alto es el PIB por habitante de un país, más alta es su tasa de actividad, o lo 
Cuadro 5. Salario medio anual según comunidad autónoma y año

\begin{tabular}{lccll}
\hline & & & & Tasa de \\
& 1995 & 2004 & Diferencia & $\begin{array}{l}\text { crecimiento } \\
\text { Andalucía }\end{array}$ \\
Cataluña & 15.271 & 16.416 & 1.145 & $7,5 \%$ \\
Diferencia & 17.844 & 19.475 & 1.631 & $9,1 \%$ \\
Cataluña (Andalucía = 100) & 117 & 119 & & \\
Convergencia & & & $-92,459$ & \\
\hline
\end{tabular}

Fuente: INE. Encuesta anual de estructura salarial. Elaboración propia.

Cuadro 6. Tasa de población activa femenina según comunidad autónoma y año

\begin{tabular}{lccll}
\hline & 1995 & $\mathbf{2 0 0 4}$ & Diferencia & $\begin{array}{l}\text { Tasa de } \\
\text { crecimiento }\end{array}$ \\
\hline Andalucía & 34,84 & 41,56 & 6,72 & 19,3 \\
Cataluña & 41,99 & 51,33 & 9,34 & 22,2 \\
Diferencia & 7,15 & 9,77 & & \\
Cataluña (Andalucía = 100) & 121 & 124 & & \\
Convergencia & & & $-76,3$ & \\
\hline
\end{tabular}

Fuente: INE. Encuesta de población activa (segundo trimestre).

que es igual, trabaja más proporción de gente. El incremento de la población activa se consigue sobre todo mediante la incorporación de la mujer al trabajo (Gobernado, 1999: 398-399). La tasa de población activa masculina es muy parecida en la mayoría de los países, lo que difiere verdaderamente es la tasa femenina. Pero este indicador de desarrollo despierta polémica en la actualidad: las mujeres siempre trabajan, en unos casos en el mercado laboral y en otros al margen del mercado. Así que la misma tarea (por ejemplo, cuidar enfermos) realizada dentro del mercado laboral está contabilizada en la tasa de población activa correspondiente, pero si se realiza al margen del mercado, no lo está (véase sobre esto Durán Heras, 2000).

De acuerdo con lo que se desprende de los datos del cuadro 6, la tasa de población activa femenina aumenta bastante en los diez años observados y en ambas comunidades autónomas. La incorporación de la mujer al mercado laboral es algo evidente. No obstante, la proporción de mujeres que trabaja en Cataluña en el año 2005 es superior a la de Andalucía (casi diez puntos porcentuales). Pero, además, la tasa en cuestión aumenta también más en Cataluña. El índice de convergencia es también aquí negativo. Andalucía incorpora sus mujeres al trabajo, pero Cataluña lo hace más deprisa.

Otro indicador de desarrollo socioeconómico es el crecimiento de población. En general, el aumento demográfico acusado suele explicarse por una mayor 
Cuadro 7. Población según comunidad autónoma y año

\begin{tabular}{lccrl}
\hline & 1995 & 2004 & Diferencia & $\begin{array}{l}\text { Tasa de } \\
\text { crecimiento }\end{array}$ \\
\hline Andalucía & 7.234 .873 & 8.039 .399 & 804.526 & 11,1 \\
Cataluña & 6.090 .040 & 7.197 .174 & 1.107 .134 & 18,2 \\
Diferencia & -1.144 .833 & -842.225 & & \\
Cataluña (Andalucía = 100) & 84 & 90 & \\
Convergencia & & \multicolumn{2}{c}{33,6} & \\
\hline
\end{tabular}

Fuente: INE.

inmigración ${ }^{10}$, y la gente va allí donde hay más posibilidades económicas, donde hay más trabajo. En cierta medida, coincide con la idea de la individuación. Tal y como se aprecia en el cuadro 7, Cataluña ha aumentado mucho su población en estos últimos doce años: un 18,2 por ciento. Andalucía también lo ha hecho, pero con menos intensidad: sólo un 11,1. En este caso, la convergencia es engañosa: Cataluña alcanzará la población de Andalucía en poco menos de treinta y cuatro años. Es decir, en este caso hay divergencia por parte de Andalucía, que parece ir a la zaga en este indicador de desarrollo ${ }^{11}$, el dato de la convergencia podría ser entendido ahora como negativo.

Seguramente, la esperanza de vida al nacer es otro indicador de desarrollo sobre el que no existe mucha polémica (aunque la relación entre PIB y mortalidad, en los países ya desarrollados, no es tan directa como pueda parecer, véase, al respecto, Soares, 2007). La discusión se centra, sobre todo, en la distinción entre tiempo vivido sin dependencia física y tiempo vivido con dependencia física de otras personas. Es obvio que la calidad de vida disminuye cuando el tiempo de vida dependiente se alarga (Durán Heras, 2004). No obstante, el poder vivir más tiempo es deseable y es también un signo de desarrollo. La esperanza de vida, según los datos del cuadro 8 , ha aumentado en las dos comunidades, pero lo ha hecho más en Cataluña. La diferencia con Andalucía ha aumentado. El dato de convergencia es negativo y además es bajo $(-26,4)$.

10. Para un repaso muy completo de la relación entre demografía y sistema social, véase Sarrible Pedroni (1991). Interesa destacar ahora el escaso potencial demográfico de la fecundidad en nuestro país, ligado en general a la incorporación de la mujer al mercado laboral sin abandonar sus tareas tradicionales (Delgado, Zamora López y Barrios, 2006; Baizán, 2006).

11. Seguramente, este indicador de desarrollo es polémico. La baja densidad de población puede identificarse como un indicador de calidad de vida o medioambiental.

Densidad de población según comunidad autónoma y años

\begin{tabular}{lrrr}
\hline & $\mathbf{1 9 9 6}$ & $\mathbf{2 0 0 7}$ & Diferencia \\
\hline Andalucía & 83 & 92 & 9 \\
Cataluña & 190 & 224 & 34 \\
Diferencia & 107 & 132 & \\
\hline
\end{tabular}


Cuadro 8. Esperanza de vida al nacer según comunidad antónoma y año

\begin{tabular}{lccc}
\hline & 1996 & 2005 & Diferencia \\
\hline Andalucía & 77,08 & 78,83 & 1,75 \\
Cataluña & 78,35 & 80,5 & 2,15 \\
Diferencia & $-1,27$ & $-1,67$ & 0,49 \\
Cataluña (Andalucía = 100) & 101,5 & 102,1 & 126,8 \\
Convergencia & & $-26,4$ & \\
\hline
\end{tabular}

Fuente: INE, elaboración propia.

Esto supone que Andalucía se separa rápidamente de Cataluña, lo que no es deseable ni discutible ${ }^{12}$.

La mortalidad infantil es un indicador de desarrollo sobre el que tampoco hay polémica. En cierta medida, explica a su vez la tasa de fecundidad ${ }^{13}$ :

12. Como es de suponer, la esperanza de vida está relacionada con la proporción de personas de más edad. Esta proporción puede entenderse también como un indicador de desarrollo, indicador que aquí no exponemos porque exige un tratamiento más detallado sobre la dependencia física. De cualquier forma, la proporción de los que han pasado la edad de sesenta y cinco años es mayor en Cataluña que en Andalucía.

La tabla siguiente sobre población dependiente y población independiente ofrece una visión rápida de la estructura de edades de las comunidades autónomas estudiadas. Esta terminología es estrictamente demográfica y tiene poco que ver con la dependencia o la independencia física de una persona concreta. En Andalucía hay más proporción de población menor de quince años; mientras que en Cataluña es superior la proporción de mayores de sesenta y cinco años. Parece que en Cataluña se ha llegado a una estructura estable. En Andalucía, sin embargo, se aprecia todavía un cambio hacia las proporciones catalanas en los últimos diez años: disminuyen los jóvenes y aumentan los viejos.

Población dependiente e independiente según años y comunidad autónoma

\begin{tabular}{|c|c|c|c|c|c|c|c|}
\hline & & \multicolumn{3}{|l|}{ Absolutos } & \multicolumn{3}{|c|}{ Porcentajes } \\
\hline & & $<15$ & $16-65$ & $>65$ & $<15$ & $15-65$ & $>65$ \\
\hline \multirow[t]{3}{*}{ Andalucía } & 1996 & 1.401 .710 & 4.882 .004 & 951.160 & 19 & 67 & 13 \\
\hline & 2007 & 1.293 .232 & 5.567 .253 & 1.178 .914 & 16 & 69 & 15 \\
\hline & Diferencia & -108.478 & 685.249 & 227.754 & -3 & 2 & 2 \\
\hline \multirow[t]{3}{*}{ Cataluña } & 1996 & 880.494 & 4.220 .310 & 989.234 & 14 & 69 & 16 \\
\hline & 2007 & 1.038 .372 & 4.975 .262 & 1.183 .540 & 14 & 69 & 16 \\
\hline & Diferencia & 157.878 & 754.952 & 194.306 & 0 & 0 & 0 \\
\hline
\end{tabular}

Fuente: INE, elaboración propia.

13. La tasa de fecundidad (número medio de hijos por mujer) es otro indicador habitual de desarrollo, aunque también es polémico. Se supone que, en general, cuanto más desarrollado sea un país, las tasas de fecundidad se mantienen en el número de mantenimiento demográfico (más o menos de 2,1 hijos). Por encima de ahí, hay falta de desarrollo. El problema surge a la hora de interpretar los datos cuando descienden de ese número de mantenimiento, como es el caso que nos ocupa (al igual que España en su totalidad, Italia o 
Cuadro 9. Tasa de mortalidad infantil (por mil nacidos vivos) según comunidad autónoma y año

\begin{tabular}{lccc}
\hline & \multicolumn{3}{c}{ Mortalidad infantil } \\
\cline { 2 - 4 } & $\mathbf{1 9 9 6}$ & $\mathbf{2 0 0 6}$ & Diferencia \\
\hline Andalucía & 6,21 & 4,61 & 1,6 \\
Cataluña & 4,12 & 3,18 & 0,94 \\
Diferencia & 2,09 & 1,43 & 0,66 \\
Cataluña (Andalucía = 100) & 66 & 69 & 59 \\
Convergencia & & 94,8 & \\
\hline
\end{tabular}

Fuente: INE, elaboración propia.

cuantas más posibilidades de supervivencia tengan los recién nacidos, más disminuirá la tasa de fecundidad. La mortalidad infantil está muy unida al nivel educativo y cultural de la población, pero sobre todo depende de la asistencia sanitaria. Según los datos del cuadro 9, la mortalidad infantil es muy baja en las dos comunidades autónomas, además, ha disminuido también en las dos. Sin embargo, la situación de Cataluña es mucho mejor que la de Andalucía: la tasa catalana es bastante inferior. La convergencia en este aspecto ( 94,8 años) apenas se vislumbra en el horizonte.

El tamaño medio del hogar ha sido considerado, desde los inicios de los estudios sociológicos del desarrollo, un indicador del mismo. Cuanto más desarrollada era una sociedad, menor era el tamaño medio de sus hogares. En realidad, esto suponía la idea, no del todo acertada, de que la familia típica de la sociedad tradicional era la extensa (tres o más generaciones conviviendo juntas) y con muchos hijos, mientras que la familia moderna era la nuclear (sólo estaba formada por dos generaciones) y con pocos hijos. En verdad, lo que marca en la actualidad a las sociedades más desarrolladas es la gran cantidad de población que vive sola, en hogares unipersonales. Es esta proporción, sobre todo, la que obliga a disminuir el número medio de personas por hogar (Bericat y Martín-Lagos, 2006). Es dudoso que vivir solo sea bueno, de ahí la posible crítica a este indicador.

De acuerdo con el cuadro 10, el tamaño medio del hogar andaluz es mayor que el catalán. En ambos casos, el tamaño del hogar disminuye, pero disminuye todavía mucho más en Cataluña. No existe convergencia: el dato al res-

Japón). De cualquier forma, se observa, tanto en Cataluña como en Andalucía, un repunte de la tasa en cuestión. El repunte es más acentuado en Cataluña.

Número medio de hijos por mujer, según comunidad autónoma y años

\begin{tabular}{lll}
\hline & 1996 & 2005 \\
\hline Andalucía & 1,327 & 1,466 \\
Cataluña & 1,15 & 1,455 \\
\hline
\end{tabular}


Cuadro 10. Tamaño medio del hogar y porcentaje de hijos nacidos de madre soltera según comunidad autónoma y año

\begin{tabular}{|c|c|c|c|c|c|c|}
\hline & \multicolumn{3}{|c|}{ Tamaño medio del hogar } & \multicolumn{3}{|c|}{ Nacidos de madre soltera } \\
\hline & 1998 & 2004 & Diferencia & 1996 & 2005 & Diferencia \\
\hline Andalucía & 3,48 & 3,17 & 0,31 & 10,57 & 25,05 & 14,48 \\
\hline Cataluña & 3,08 & 2,78 & 0,3 & 13,9 & 29,75 & 15,85 \\
\hline Diferencia & 0,4 & 0,39 & 0,01 & 3,33 & 4,7 & 1,37 \\
\hline Cataluña $($ Andalucía $=100)$ & 89 & 88 & 97 & 132 & 119 & 109 \\
\hline Convergencia & \multicolumn{3}{|c|}{-79.8} & \multicolumn{3}{|c|}{24,2} \\
\hline
\end{tabular}

Fuente: INE, elaboración propia.

pecto es negativo $(-79,8)$, lo que indica que Cataluña se separa aún más de la tendencia de Andalucía.

El último indicador de desarrollo, objeto de análisis de la convergencia, es algo atípico. Se trata de la proporción de hijos nacidos de madre soltera (véase también cuadro 10). En los países nórdicos, la proporción de hijos de madre soltera supera el 50 por ciento de los nacidos. Esta tendencia ya se apreció en los Estados Unidos hace más de treinta años (Santi, 1988). Este incremento se puede explicar, en parte, por motivos burocráticos: las parejas conviven en situaciones de hecho, pero esa relación no se traduce en los datos estadísticos. Otra explicación es que las ayudas oficiales a las madres solteras, donde las haya, estimulan la formación de hogares monoparentales (Monnier, 1989). De cualquier forma, los países más desarrollados presentan tasas más altas de hijos de esta categoría que los menos desarrollados. Y en esto las andaluzas se han sumado a la modernidad con entusiasmo. Existe convergencia al respecto (24,2 años) entre las dos comunidades.

Resumiendo la información anterior, las dos comunidades tienden a mejorar notablemente los indicadores de desarrollo en los últimos diez años. Son sociedades cada vez más modernas. Sin embargo, Cataluña va más deprisa en este proceso. Andalucía tiende a converger con Cataluña en los indicadores relacionados con el PIB, especialmente el del PIB por habitante. Sin embargo, el indicador de convergencia es negativo en casi todos los demás indicadores: el salario medio anual, la tasa de actividad femenina, el crecimiento de la población, la esperanza de vida al nacer y el tamaño del hogar. En todos estos, Andalucía va en la dirección correcta, pero Cataluña avanza mucho más deprisa. Hay otros dos indicadores con una convergencia positiva: la tasa de mortalidad infantil y el número de nacidos de madre soltera. La tasa de mortalidad infantil andaluza, sin embargo, tiene un acercamiento muy lento, muy a largo plazo, con la catalana.

Hay que recordar que, pese al acercamiento del PIB por habitante andaluz al catalán, éste es casi vez y media superior al de Andalucía. Posiblemente esta diferencia justifique la mayor velocidad de desarrollo en Cataluña. 


\section{La individuación}

Los datos que siguen ahora son de diferente carácter que los anteriores. Se trabaja, a continuación, con desigualdades de ingresos: entre la provincia con el PIB más alto y la que lo tiene más bajo, entre los salarios de los hombres y los de las mujeres, entre jóvenes y adultos, entre la ocupación laboral mejor pagada y la peor, entre el sector de producción mejor pagado y el peor y entre tipos de contrato. Las desigualdades pueden observarse de dos formas: la primera, en términos absolutos, y, la segunda, en proporción a la media. Ambas lecturas son útiles y tienen su propia interpretación. Las diferencias proporcionales a la media son menores y se acercan más a los datos esperados según el modelo teórico.

Obsérvese que la interpretación de los cuadros que vienen ahora es diferente de la interpretación de los anteriores. Ahora tratamos con diferencias, con desigualdades, dentro de cada casilla. Se supone que cuanto menores sean las diferencias aludidas arriba, mayor individuación existe en esa sociedad.

Las diferencias más evidentes que indican poco desarrollo son las diferencias territoriales. A peor distribución territorial de la riqueza, menor nivel de desarrollo. Los datos sobre el PIB por provincias de ambas comunidades autónomas nos pueden ayudar a comprender mejor el proceso. Por supuesto, la comparación no es del todo correcta, ya que en Andalucía hay ocho provincias y en Cataluña, cuatro. Andalucía tiene un territorio mucho más grande que Cataluña y a mayor tamaño siempre hay mayor heterogeneidad.

En el cuadro 11, se dan los datos absolutos de las diferencias máximas entre provincias atendiendo a su PIB. En el cuadro 12, están los porcentajes de cada desigualdad sobre el PIB por habitante de cada comunidad autónoma y año (de ahora en adelante, se presentan nada más los datos relativos).

Según los datos relativos (cuadro 12), las desigualdades entre provincias son mucho más grandes en Andalucía que en Cataluña, tanto en 1995 como nueve años después (como era de esperar según la teoría repasada anteriormente). Así mismo y en contra de lo esperado, el paso del tiempo ha acrecentado aún más esas desigualdades en las dos comunidades, pese al crecimiento económico de ambas. No obstante, el incremento de desigualdades ha sido más acusado en Cataluña que en Andalucía. La distancia entre Andalucía y Cataluña al respecto ha disminuido: si damos el valor de 100 a las diferencias

Cuadro 11. Diferencias del PIB (a precios constantes de 1995) por habitante y año (€) entre la provincia más rica y la más pobre de cada comunidad autónoma

\begin{tabular}{llll}
\hline $\begin{array}{l}\text { Andalucía } \\
\text { (a) }\end{array}$ & $\begin{array}{l}\text { Cataluña } \\
\text { (b) }\end{array}$ & $\begin{array}{l}\text { Cataluña } \\
\text { (Andalucía = 100) }\end{array}$ \\
\hline 1995 & (Almería-Granada) 1.546 & (Tarragona-Lérida) 1.259 & 81 \\
2003 & (Almería-Jaén) 2.449 & (Tarragona-Lérida) 2.320 & 95 \\
\hline
\end{tabular}

Fuente: INE. Contabilidad regional de España. Elaboración propia. 
Cuadro 12. Porcentajes de cada desigualdad entre la provincia más rica y la más pobre (cuadro 5) sobre el PIB correspondiente (cuadro 2)

\begin{tabular}{lllll}
\hline Año & $\begin{array}{l}\text { Andalucía } \\
\text { (a) }\end{array}$ & $\begin{array}{l}\text { Cataluña } \\
\text { (b) }\end{array}$ & Diferencia & $\begin{array}{l}\text { Cataluña } \\
\text { (Andalucía = 100) }\end{array}$ \\
\hline 1995 & 19 & 9 & 10 & 49 \\
2004 & 23 & 15 & 8 & 64 \\
Incremento & $21 \%$ & $67 \%$ & & \\
\hline
\end{tabular}

Fuente: INE. Contabilidad regional de España. Elaboración propia.

interprovinciales andaluzas, Cataluña llega al valor 64 en el año 2004. Es decir, Cataluña ha aumentado su desigualdad territorial interna y se ha acercado a la de Andalucía, lo cual no es una buena noticia.

De cualquier forma y según esos mismos datos, las desigualdades entre provincias en Andalucía son todavía más acusadas que las desigualdades correspondientes en Cataluña, de acuerdo con el supuesto teórico. No obstante, la tendencia sigue siendo la misma: las desigualdades aumentan en ambas comunidades autónomas, aunque aumentan más deprisa en Cataluña, sin llegar, por supuesto, a las desigualdades territoriales andaluzas. El pronóstico teórico insiste, recordemos, en que el desarrollo se consigue cuando disminuyen las diferencias entre categorías sociales (o territoriales como es el caso), cosa que no ocurre ahora.

La Encuesta anual de estructura salarial es más útil para los objetivos de este epígrafe. Tiene tres inconvenientes principales: primero, la clasificación de los sectores productivos es extraña (no aparece la agricultura ni ningún tipo de sector primario); otro inconveniente es que los datos de 1995 están en miles de pesetas que hay que convertir en euros, y, el tercero, que los datos no se ofrecen en precios constantes. De todos modos, no importan mucho estos inconvenientes, porque se trata de comparar las dos comunidades y sospechamos que los posibles errores son exactamente iguales para ambas.

Las diferencias entre hombres y mujeres constituyen un indicador muy usado de desarrollo. Las diferencias en el nivel de educación formal, de ocupación, de ingresos, etc. constituyen un aviso claro de desarrollo. Cuanto mayor sea la diferencia, menor desarrollo tiene el país (Sen y Grown, 1995). En el cuadro 13, se ofrecen los datos ponderados sobre la media de la diferencia entre el salario medio de los hombres y el salario medio de las mujeres para cada año y comunidad. De los mismos se colige que las diferencias relativas entre los salarios de los hombres y los de las mujeres disminuyen en ambas comunidades, como era de esperar según el modelo teórico. Disminuyen bastante más en Andalucía que en Cataluña, pese a que las diferencias son inferiores en Andalucía. La distancia entre una y otra comunidad aumenta a favor, en este caso, de Andalucía: los salarios son más igualitarios en ella.

Algo parecido ocurre con las diferencias salariales según las categorías de edad, aunque con distancias menos acusadas entre comunidades. La catego- 
Cuadro 13. Porcentajes de la desigualdad de salarios según sexo sobre el salario medio de cada comunidad autónoma y año

\begin{tabular}{lllcl}
\hline Año & $\begin{array}{l}\text { Andalucía } \\
\text { (a) }\end{array}$ & $\begin{array}{l}\text { Cataluña } \\
\text { (b) }\end{array}$ & Diferencia & $\begin{array}{l}\text { Cataluña } \\
\text { (Andalucía = 100) }\end{array}$ \\
\hline 1995 & 37 & 40 & -3 & 108 \\
2004 & 29 & 39 & -10 & 135 \\
Incremento & $-22 \%$ & $-3 \%$ & & \\
\hline
\end{tabular}

Fuente: INE. Encuesta anual de estructura salarial. Elaboración propia.

Cuadro 14. Porcentajes de la desigualdad de salarios según edad sobre el salario medio de cada comunidad autónoma y año

\begin{tabular}{lllcc}
\hline Año & $\begin{array}{l}\text { Andalucía } \\
\text { (a) }\end{array}$ & $\begin{array}{l}\text { Cataluña } \\
\text { (b) }\end{array}$ & Diferencia & $\begin{array}{l}\text { Cataluña } \\
\text { (Andalucía = 100) }\end{array}$ \\
\hline 1995 & 105 & 99 & 6 & 94 \\
2004 & 75 & 76 & -1 & 101 \\
Incremento & $-29 \%$ & $-23 \%$ & & \\
\hline
\end{tabular}

Fuente: INE. Encuesta anual de estructura salarial. Elaboración propia.

ría de edad peor remunerada es la de "menos de 20 años», como era de esperar, en ambas comunidades y en los dos años considerados. Así mismo, la categoría mejor pagada es la de " 50 a 59 años», también en las dos comunidades, en las dos etapas marcadas y como era previsible de nuevo. En el cuadro 14, se ven los datos de esas diferencias ya ponderadas por la media de salarios correspondiente. Las diferencias por edad en los salarios disminuyen claramente en las dos comunidades (no olvidemos que se trabaja ahora con datos en los que no se tiene en cuenta el crecimiento de precios al consumo). Disminuyen algo más, muy poco más, en Andalucía. Las diferencias de comunidad son mínimas. En ambas, la desigualdad relativa de salarios según edad en el último año es muy parecida.

Hacemos un cálculo parecido con las diferencias de salario medio de las veinte categorías ocupacionales (CNO-94): se calcula para cada comunidad la diferencia máxima de salarios entre categorías ocupacionales, es decir, la diferencia entre la categoría mejor pagada y la peor pagada. En ambas comunidades y en los dos años, la categoría ocupacional que recibe los emolumentos más elevados es la A (directores de empresa y de la Administración pública). La que menos es la $S$ (trabajadores no cualificados de los servicios), salvo en Andalucía en 1995, cuya categoría en cuestión fue la T (peones de la construcción, industria y transporte). En Andalucía, nueve años después, la categoría ocupacional $S$ se convierte en la peor pagada, como en Cataluña. En el cuadro 15, se presentan los datos de esas diferencias de salario ocupacional ponderadas ya por la media de salarios por habitante de cada comunidad. 
Cuadro 15. Porcentajes de la desigualdad de salarios según categorías ocupacionales sobre el salario medio de cada comunidad autónoma y año

\begin{tabular}{lllcc}
\hline Año & $\begin{array}{l}\text { Andalucía } \\
\text { (a) }\end{array}$ & $\begin{array}{l}\text { Cataluña } \\
\text { (b) }\end{array}$ & Diferencia & $\begin{array}{l}\text { Cataluña } \\
\text { (Andalucía = 100) }\end{array}$ \\
\hline 1995 & 185 & 172 & 13 & 93 \\
2004 & 213 & 275 & -62 & 129 \\
Incremento & $15 \%$ & $60 \%$ & & \\
\hline
\end{tabular}

Fuente: INE. Encuesta anual de estructura salarial. Elaboración propia.

Las desigualdades de salario según las categorías ocupacionales son las más acusadas de todas las tenidas en cuenta en este trabajo. Además, tales desigualdades han aumentado en las dos comunidades autónomas en los nueve años considerados. No obstante, la desigualdad ocupacional ha aumentado muchísimo más en Cataluña, pese a todo pronóstico teórico. Andalucía es menos desigualitaria en el 2004 que Cataluña, al revés que en el año 1995. Estos datos están plenamente de acuerdo con la afirmación de Goldthorpe (2007b) citada arriba, de que en la actualidad, en las sociedades más desarrolladas, se ha producido un gran aumento de los ingresos de las clases ocupacionales superiores.

La misma tarea se ha llevado a cabo en el cuadro 16, pero en este caso a partir de los sectores de producción considerados en la encuesta anual de estructura salarial. En esta encuesta, los sectores son tres: industria (en donde se incluyen las empresas extractivas), construcción y servicios. En los dos años considerados, el sector mejor pagado es el de la industria, tanto en Andalucía como en Cataluña. Sin embargo, hay un cambio en el sector peor pagado. En 1995, era el de la construcción, en las dos comunidades. En el 2004, el peor pagado es el de los servicios, también en las dos comunidades. En el cuadro 16 , se ofrecen los resultados ya ponderados de acuerdo con el criterio repetidamente usado.

Los datos indican que la desigualdad de salarios según sectores de producción es muy baja en las dos comunidades. Indican también que en Andalucía se ha producido un gran acercamiento entre tales salarios, mientras que en Cataluña ha ocurrido todo lo contrario, siempre dentro de unas escasas diferencias entre comunidades y desigualdades entre sectores de producción también muy pequeñas. De cualquier forma, Cataluña presenta desigualdades al respecto mayores que las de Andalucía.

La encuesta de estructura salarial distingue dos tipos de contrato: el indefinido y el de duración determinada. El empleo temporal se ha mantenido en unas proporciones constantes desde su implantación allá por los años ochenta del siglo pasado (Polavieja, 2005 y 2006). En ambas comunidades y en los dos años los asalariados que reciben sueldos más altos son los que disfrutan de un contrato indefinido. Según los datos del cuadro 17, no parece que exista una gran distancia entre Cataluña y Andalucía. Se observan dos matices inte- 
Cuadro 16. Porcentajes de la desigualdad de salarios según sector de producción sobre el salario medio de cada comunidad autónoma y año

\begin{tabular}{lllcc}
\hline Año & $\begin{array}{l}\text { Andalucía } \\
\text { (a) }\end{array}$ & $\begin{array}{l}\text { Cataluña } \\
\text { (b) }\end{array}$ & Diferencia & $\begin{array}{l}\text { Cataluña } \\
\text { (Andalucía = 100) }\end{array}$ \\
\hline 1995 & 35 & 12 & 23 & 33 \\
2004 & 13 & 23 & -11 & 182 \\
Incremento & $-63 \%$ & $92 \%$ & & \\
\hline
\end{tabular}

Fuente: INE. Encuesta anual de estructura salarial. Elaboración propia.

Cuadro 17. Porcentajes de la desigualdad de salarios según tipo de contrato sobre el salario medio de cada comunidad autónoma y año

\begin{tabular}{lllcc}
\hline Año & $\begin{array}{l}\text { Andalucía } \\
\text { (a) }\end{array}$ & $\begin{array}{l}\text { Cataluña } \\
\text { (b) }\end{array}$ & Diferencia & $\begin{array}{l}\text { Cataluña } \\
\text { (Andalucía = 100) }\end{array}$ \\
\hline 1995 & 67 & 62 & 5 & 93 \\
2004 & 39 & 41 & -1 & 103 \\
Incremento & $-42 \%$ & $-34 \%$ & & \\
\hline
\end{tabular}

Fuente: INE. Encuesta anual de estructura salarial. Elaboración propia.

resantes. En primer lugar, las diferencias entre los salarios de ambos tipos de contrato son mayores en 1995 que once años después. Es de prever que esta diferencia disminuya aún más. Lo lógico es pensar que la inseguridad en el puesto de trabajo se compense con salarios más elevados, es decir, que los salarios con contrato indefinido desciendan y los de los contratos a duración determinada aumenten. En segundo lugar, esas diferencias han disminuido algo menos en Cataluña que en Andalucía, siempre teniendo en cuenta que apenas hay distancias entre las dos comunidades. En líneas generales, los datos del cuadro 17 están de acuerdo con las previsiones lógicas del modelo teórico.

Como se indicó al principio del texto, el análisis de la individuación supone información de la dispersión sobre la media aritmética. Es un análisis justificado en función del desarrollo de la desigualdad. Pues bien, resumiendo los datos relativos anteriores, se puede afirmar que la desigualdad en la mayoría de los indicadores observados disminuye en las dos comunidades. Sólo aumenta en la distribución del PIB por habitante en las provincias, tanto en Cataluña como en Andalucía (si bien lo hace mucho más en Cataluña); en la desigualdad de salarios en las veinte categorías ocupacionales (también de forma más acusada en Cataluña) y en la desigualdad de salarios por sectores de producción en Cataluña (en Andalucía, por el contrario, disminuye).

Disminuyen, por el contrario, la desigualdad de salarios por sexo (más acusadamente en Andalucía), la desigualdad de salarios por edad (algo más en Cataluña), por sectores de producción en Andalucía, y la desigualdad de salarios según tipo de contrato. 
En general, las diferencias de evolución de estas desigualdades no son muy acusadas. Destaca, sin embargo, la rápida discrepancia entre comunidades surgida en la desigualdad de salarios según sectores de producción (Cataluña ha aumentado muchísimo la desigualdad en este tema). Se aprecia algo de discrepancia en la desigualdad de salarios por sexo (con menor desigualdad en Andalucía) y en la desigualdad según categorías ocupacionales (también con menor desigualdad en Andalucía). Las otras desigualdades siguen evoluciones parecidas.

\section{Conclusiones}

Nuestro objetivo ha sido constatar el desarrollo económico de Andalucía en los años del crecimiento del PIB (1995-2006). Para ello, se han seguido dos métodos: en primer lugar, un estudio comparativo con Cataluña y, en segundo lugar, la revalidación de la teoría de la modernidad en su versión más concreta de desarrollo socioeconómico.

Es obvio que Cataluña tiene un nivel de desarrollo económico superior al de Andalucía. El PIB por habitante del año 2006 en Cataluña alcanza los $25.612 €$ mientras que el de Andalucía se queda en $16.963 €$. Es una diferencia considerable. Los demás indicadores dan resultados parecidos, por eso hemos escogido Cataluña como criterio de modernización. Como muestra, véanse los siguientes datos de diversas fuentes:

- La esperanza de vida al nacer según el INE en el año 2005 es mayor en Cataluña (80,5 años) que en Andalucía (78,8 años).

- La tasa de mortalidad infantil según el INE en el año 2005 es en Cataluña de 2,85, en tanto que en Andalucía subía a 4,75. Este dato es muy significativo.

- El tamaño medio por hogar (Encuesta continua de presupuestos familiares, del INE) en el año 2004 en Cataluña es de 2,78 personas y el de Andalucía, de 3,17 .

- La proporción de hogares con ordenador (Encuesta continua de presupuestos familiares, del INE) también en el 2004 es del 51,06 por ciento en Cataluña y del 40,93 en Andalucía.

- La proporción de hogares conectados a Internet en el 2006 (Encuesta de equipamiento y uso de tecnologías de la información y la comunicación, primer semestre, del INE) es en Cataluña el 47 por ciento y en Andalucía, el 32 por ciento.

- La tasa de población activa femenina en Cataluña en el 2005 (Encuesta de población activa) era del 51,15 y la de Andalucía, del 41,51.

La explicación de la distancia entre Andalucía y Cataluña debe ir más allá de los simples indicadores usados arriba. Tiene que ver sobre todo con dos circunstancias. La primera es de carácter eminentemente geográfico: Cataluña está al lado de Francia y Andalucía, al lado de Marruecos. Y está claro que no es lo mismo estar junto al resto de Europa que junto a África. 
La segunda circunstancia, de carácter socio-histórico, es la tradicional falta de inversión en educación formal en Andalucía hasta bien entrado el siglo XX. En el censo de 1970, la proporción de población que no tenía estudios más la que no sabía leer ni escribir en la provincia de Málaga suponía el 70 por ciento. De ahí la doble necesidad andaluza: por un lado, incrementar los medios de comunicación de ideas, personas y cosas para acercarnos a Europa; por otro, invertir tanto en educación básica como en educación de élite. Claro que los beneficios de toda esa inversión se obtienen a medio o incluso a largo plazo. Toda esa tarea, ya comenzada, necesita su tiempo para ver los resultados.

Volviendo a nuestros objetivos, tanto Andalucía como Cataluña están sufriendo procesos acusados de modernización. Los indicadores de ambas comunidades cambian claramente en la dirección prevista de desarrollo. No obstante, como se dijo arriba, Cataluña va muy por delante. Pese a dicha gran diferencia actual entre ambas comunidades, los datos indican un cierto acercamiento, sobre todo con los indicadores relacionados con el PIB. Así, la tasa de crecimiento del PIB por habitante de Andalucía durante el período 19952004 (33 por ciento) es mayor que la de Cataluña (18 por ciento). Hay, por lo tanto, convergencia económica con Cataluña. Si se mantiene tal diferencia en la tasa, es posible un acercamiento, pero a medio o largo plazo (treinta y ocho años según el indicador de convergencia usado). Cataluña está demostrando tener un gran potencial de crecimiento y como paradigma a seguir se vuelve problemática. En el resto de indicadores no hay convergencia positiva: el salario medio anual, la tasa de actividad femenina, el crecimiento de la población, la esperanza de vida al nacer y el tamaño del hogar. Todos estos indicadores mejoran en ambas comunidades, pero lo hacen mucho más deprisa en Cataluña. La tasa de mortalidad infantil tiene una convergencia positiva, pero muy a largo plazo (95 años): las tendencias en este caso son casi paralelas.

Así mismo, los indicadores de dispersión o desigualdad en el reparto de las mejoras propias de la modernidad (recordemos que a más individuación menos desigualdad) han disminuido en ambas comunidades. Sólo ha aumentado la desigualdad territorial por provincias, tanto en Cataluña como en Andalucía (mucho más en Cataluña), la desigualdad de salarios según categorías ocupacionales (también más acusadamente en Cataluña) y la desigualdad de salarios según sectores de producción, pero sólo en Cataluña (en Andalucía, por el contrario, disminuye). Disminuye en las dos comunidades la desigualdad de salarios por sexo (más acusadamente en Andalucía), la desigualdad de salarios por edad (algo más en Cataluña) y la desigualdad de salarios según tipo de contrato. Desciende también la desigualdad de salarios por sectores de producción en Andalucía (aumenta en Cataluña, tal y como se dijo antes).

No son muy acusadas las discrepancias en la evolución de esas desigualdades. En Cataluña ha aumentado mucho más la desigualdad de salario por sectores de producción (en Andalucía disminuye); la discrepancia de salarios según el sexo disminuye más deprisa en Andalucía y la desigualdad de salarios 
según categorías ocupacionales aumenta también mucho más deprisa en Cataluña. Las demás desigualdades evolucionan de forma parecida.

Si Cataluña se hubiera limitado a culminar el proceso de desarrollo (proceso en forma de $S$ ) en el que estaba embarcada hace quince años, hubiera sido fácil alcanzar su mismo nivel. Sin embargo, como se sabe, el desarrollo consiste en un encadenamiento de procesos, en un encadenamiento en forma de $S$. No es un encadenamiento eterno, tiene también marcha atrás, pero se suele dar más a menudo cuanto más alto es el nivel de vida de esa sociedad. En resumen, Cataluña se encuentra en otro proceso de desarrollo distinto del de hace quince años. Y esto se aprecia sobre todo en los datos sobre difusión del desarrollo.

El modelo teórico simple (de un solo proceso en forma de $S$ ) predecía una mayor homogeneidad (menor desigualdad) a medida que aumentara la riqueza del país (medida por el PIB). Este modelo de difusión del desarrollo se correspondía bien con la situación de hace quince años (Gobernado, 1996a). Los datos obtenidos entonces corroboraban completamente el mismo. En realidad, el crecimiento de la riqueza solo podía lograrse, a partir de un momento, haciendo partícipe de la misma a las categorías sociales menos favorecidas (mujeres, jóvenes, medio rural, etc.). Esta situación ha cambiado. La globalización, el desarrollo tecnológico e informacional y el nivel de vida previamente alcanzado han permitido un nuevo despegue en un nuevo proceso de desarrollo. Se aprecia en la actualidad un incremento acusadísimo de la riqueza sin necesidad de acudir, por ahora, a su difusión entre las categorías menos favorecidas.

No obstante, perduran algunos rasgos propios de la modernización en la nueva situación. Se aprecia una mayor igualdad relativa entre los salarios de hombres y mujeres; entre los de los jóvenes y los adultos, y entre los que tienen diferente tipo de contrato laboral. Por el contrario, las diferencias salariales entre las categorías ocupacionales han aumentado considerablemente. Incluso han aumentado más en Cataluña, en contra de la predicción del modelo de modernización clásico y dando la razón a Goldthorpe (2007b). También ha aumentado la desigualdad espacial (según provincias) en el reparto del PIB especialmente en Andalucía, en contra también de la teoría.

El modelo de modernización simple no sirve, al menos tanto como hace quince años. La superación de la etapa moderna (etiquétese como se quiera: postmodernización, postfordismo, sociedad de la información, globalización, etc.) dio un especial empujón a la creación de riqueza. Cataluña se encuentra inmersa ahora en un nuevo proceso de desarrollo. Más concretamente, está en el momento de mayor cambio en ese proceso: en el momento en el que la curva en forma de $S$ toma la tendencia claramente ascendente. En ese momento, la desigualdad adquiere de nuevo el valor más acusado. No obstante, perduran valores igualitarios en algunos campos de los que ya no se puede prescindir, como se indicó arriba.

Por su parte, Andalucía se encuentra más cerca del final del proceso de desarrollo de hace quince años. Su riqueza ha aumentado considerablemente 
durante la época citada, la difusión del desarrollo fue notable y hay más igualdad relativa de ingresos que en Cataluña según las distintas categorías sociales consideradas. Todo ello hace pensar que está culminando su anterior proceso de desarrollo social y económico. Cataluña, por su parte, da la sensación de haberse subido a otro tren más rápido.

Todo ello, al menos, antes de la crisis económica que padecemos en la actualidad y que merece atención aparte.

\section{Referencias bibliográficas}

AleXander, J.C. (2000). «Moderno, anti, post y neo: Cómo se ha intentado comprender en las teorías sociales el "nuevo mundo" de "nuestro tiempo"». En: ALEXANDER, J.C. Sociología cultural. Barcelona: Anthropos, 55-126.

AnAND, S. y Sen, A. (2000). «Human development and economic sustainability». World Development, 28 (12), 2029-2049.

Aron, R. (1996). «Theorie du développement et ideologies de notre temps». En: ARON, R. Une histoire du XXe. siècle. París: Plon, 587-609.

ARRIGI, G. y SiLVER, B.J. (2001). Caos y orden en el sistema-mundo moderno. Madrid: Akal.

BAIZÁN, P. (2006). «El efecto del empleo, el paro y los contratos temporales en la baja fecundidad española de los años 90». Revista Española de Investigaciones Sociológicas, $115,223-253$.

BECK, U. (2000). The brave new world of work. Cambridge: Polity Press.

BELL, D. (1976). El advenimiento de la sociedad post-industrial. Madrid: Alianza.

BERICAT, E. y MARTíN-LAGOS, M.D. (2006). La transformación de los hogares españoles y andaluces. Sevilla: Centro de Estudios Andaluces.

BLACK, C.E. (1979). «La dinámica de la modernización: un repaso general». En: Nisbet, R.; Kuhn, Th. S. y White, L. Cambio social. Madrid: Alianza, 226-256.

BOLDRIN, M. y CANOVA, F. (2001). «Inequality and convergence in Europeans regions: reconsidering European regional policies». Economic Policy, abril, 206-253.

Brunet, I. y Böcker, R. (2007). Desarrollo, industria y empresa. Madrid: Tecnos.

CAFAGNA, L. (1992). «Modernización activa y modernización pasiva». En: CARNERO ARBAT, T. (ed.). Modernización, desarrollo político y cambio social. Madrid: Alianza, 221-234.

CAMPO, S. del (dir.) (1972). Los indicadores sociales a debate. Madrid: Euramérica.

Cardoso, F.H. y Faletto, E. (1979). Dependency and development in Latin America. Berkeley: University of California Press.

CARNero ARBAT, T. (1992). Modernización, desarrollo político y cambio social. Madrid: Alianza Universidad.

CASTell, M. (1998). La era de la información. Vol. 1. La sociedad red. Madrid: Alianza.

Cummins, R.A. (2000). «Objective and subjective quality of life: An interactive model». Social Indicators Research, 52, 55-72.

Delgado, M.; Zamora López, F, y Barrios, L. (2006). «Déficit de fecundidad en España: Factores demográficos que operan sobre una tasa muy inferior al nivel de reemplazo». Revista Española de Investigaciones Sociológicas, 115, 197-222.

Deutsch, K. (1961). «Social movilization and political development». American Political Science Review, 55, 17-24. 
Durán Heras, M.A. (2000). La contribución del trabajo no remunerado a la economía española. Madrid: Instituto de la Mujer. Estudios; 63.

- (2004). "La calidad de muerte como componente de la calidad de vida». Revista Española de Investigaciones Sociológicas, 106, 9-32.

ECKERSLEY, R. (2000). "The state and fate of nations: Implications of subjective measures of personal and social quality of live». Social Indicators Research (Holanda), 52, 3-27.

EISENSTADT, S.N. (1964). «Breakdowns of modernization». Economic Development and Cultural Change, 25, suplemento, 67-98.

Entrena Durán, F. (2001). Modernidad y cambio social. Madrid: Trotta.

Gobernado, R. (1994). «Modernidad y estratificación social: Análisis comparativo de las estructuras sociales de Andalucía y Cataluña». Revista Española de Investigaciones Sociológicas, 67, 67-108.

- (1996a). "Introducción». En: GobernAdo, R. (coord.). Análisis comparado de las estructuras sociales de Andalucía y Cataluña. Málaga: Universidades de Málaga y Almería, 7-14.

- (1996b). «Los límites de la expansión educativa». Revista Española de Pedagogía, 205, 487-510.

- (1996c). «El logro ocupacional en España, veinte años después». Revista Española de Investigaciones Sociológicas, 74, 209-224.

- (1999a). "Desigualdad y clases sociales». En: REQUENA, F. Sociedad, cultura y desarrollo: Apuntes para un análisis comparado entre España y los Estados Unidos. Málaga: Universidades de Málaga y Almería, 21-64.

- (1999b). «Estructura ocupacional de Andalucía». En: MoYANO, E. y PÉrEz YRUELA, M. (cords.). Informe social de Andalucía (1978-1998). Córdoba: IESA, 397-418.

- (2002). "Análisis de la adscripción a valores». Revista Internacional de Sociología, 33, 47-66.

- (2004). «La cultura arbitraria. Operativización del concepto». Revista Internacional de Sociología, 37, 29-46.

- (coord.) (1996a). Análisis comparado de las estructuras sociales de Andalucía y Cataluña. Málaga: Universidades de Málaga y Almería.

Goesling, B. (2001). "Changing income inequalities within and between nations: New evidence». American Sociological Review, 66, 745-761.

GoldTHORPE, J.H. (2007a). "Current issues in comparative macrosociology». En: GOlDTHORPE, J.H. On sociology, second edition. Volume one: Critique and program. Stanford (California): Stanford University Press, 39-60.

- (2007b). «Globalisation and social class». En: GOLDTHORPE, J.H. On sociology, second edition. Volume one: Critique and program. Stanford (California): Stanford University Press, 91-116.

HeLd, D. y McGRew, A. (2003). Globalización / Antiglobalización: Sobre la reconstrucción del orden mundial. Barcelona: Paidós.

INGLEHART, R. (1997). Modernization and postmodernization: Cultural, economic and political change in 43 societies. Princenton: Princenton University Press.

INGLEHART, R. y WelZEL, Ch. (2006). Modernización, cambio cultural y democracia: La secuencia del desarrollo humano. Madrid: CIS.

INKELES, A. (1960). «Industrial man: The relation of status to experience, perception and value». American Journal of Sociology, LXVI (1), julio, 1-31.

INKELES, A. y SMITH, D.H. (1974). Becoming modern: Industrial change in six developing countries. Cambridge: MA: Harvard. 
KocH, M. (2006). Roads to post-fordism: Labour markets and social structures in Europe. Hampshire (Inglaterra): Ashgate.

Kumar, K. (2005). From post-industrial to post-modern society. New theories of the contemporary world. Malden (Estados Unidos), Oxford (Reino Unido), Carlton (Australia): Blackwell Publishing.

KuZneTS, S. (1973). Crecimiento económico moderno. Madrid: Aguilar.

López, A. y Uldemolins, E. (2007). «Sociología del desarrollo». En Pérez YRUelA, M. La sociología en España. Madrid: CIS y FES.

Maestro Yarza, I. y Martínez Peinado, J. (2003). «La pobreza humana y su feminización en España y las comunidades autónomas». Revista Española de Investigaciones Sociológicas, 104, 57-90.

MANCHA, T. (2001). «Integración económica y desigualdades regionales: El caso español en el contexto de la Unión Europea». En: MANCHA, T. y SOTELSEK, D. (dirs.). Convergencia económica e integración: La experiencia en Europa y América Latina. Madrid: Pirámide.

Marchante Mera, A.J.; Ortega Aguaza, B. y Sánchez Maldonado, J. (2006). «Las dimensiones del bienestar en las comunidades autónomas españolas: Un análisis de sigma y gamma-convergencia». Cuadernos de Ciencias Económicas y Empresariales, 50 y 51, 123-141.

Miguel, A. de; Díez Nicolás, J. y Medina Medina, A. (1967). Tres estudios para un sistema de indicadores sociales. Madrid: Euramérica.

Monnier, A. (1989). «Bilan de la politique familiale en République Démocratique Allemande: un réexamen». Population, 44 (2), 379-393.

Myrdal, G. (1980). Contra corriente: Ensayos criticos sobre economía. Barcelona: Ariel.

PolaviejA, J.G. (2005). "Desregulación parcial y desigualdad horizontal en España». Revista Internacional de Sociología, 41, 3-36.

- (2006). «¿Por qué es tan alta la tasa de empleo temporal?: España en perspectiva comparada». Revista Española de Investigaciones Sociológicas, 113, 77-108.

REQUENA, F. (coord.) (1999). Sociedad, cultura y desarrollo: Apuntes para un análisis comparado entre España y los Estados Unidos. Málaga: Universidades de Málaga y Almería.

RoberTs, B.R.; CUSHING, R.G. y WoOD, Ch. (1995). «Introduction». En: RoberTS, B.R.; Cushing, R.G. y Wood, Ch. (eds.). The sociology of development (2 vols.). Aldershot (Reino Unido) y Brookfield (Estados Unidos), Edgar Elgar Publishing Company, XIX-XXV.

Roberts, B.R.; Cushing, R.G. y Wood, Ch. (eds.) (1995). The sociology of development (2 vols.). Aldershot (Reino Unido) y Brookfield (Estados Unidos): Edgar Elgar Publishing Company.

Rossem, R.V. (1996). "The world system paradigmas general theory of development: a cross-national test». America Sociological Review, 61, octubre, 508-529.

SANTI, L. (1988). "The demographic context of recent change in the structure of American households». Demographic. Population Association of America, 25 (4), 509-519.

Sarrible Pedroni, G. (1991). Población y desigualdad social. Madrid: CIS.

SEN, G. y GROwN, C. (1995). «Gender and class in development experience». En: RoberTs, B.R.; CuSHING, R.G. y WoOD, Ch. (eds.) (1995). The sociology of development. Aldershot (Reino Unido) y Brookfield (Estados Unidos), Edgar Elgar Publishing Company, vol. 1, 395-430.

Simmel, G. (1986). El individuo y la libertad: ensayos de crítica cultural. Barcelona: Península. 
SOARES, R.R. (2007). "On the determinants of mortality reductions in the developing world». Population and Development Review, 33(2), 247-287.

SolÉ, C. (1976). Modernización: un análisis sociológico. Barcelona: Península.

- (1987). Ensayos de teoría sociológica: Modernización y postmodernización. Madrid: Paraninfo.

SzTOMPKA, P. (1995). Sociología del cambio social. Madrid: Alianza.

Todaro, M.P. (1982). Economía para un mundo en desarrollo. México: Siglo XXI.

WallersteIn, I. (1984). The politics of the world economy: The states, the movements and the civilizations. Cambridge: Cambridge University Press.

Welzel, Ch; INGLEHART, R. (2005). «Liberalism, postmaterialism, and the growth of freedom». International Review of Sociology, 15 (1), 81-108.

Welzel, Ch.; Inglehart, R. y Klingemann, H.-D. (2003). "The theory of human development: A cross-cultural analysis». European Journal of Political Research, 42, 341-379. 